\title{
MARXISMO E PEDAGOGIA ${ }^{1}$
}

Dermeval Saviani ${ }^{2}$

\section{RESUMO:}

Partindo dos diferentes sentidos do verbete "socialismo" o artigo aborda as relações entre marxismo, educação e pedagogia para esclarecer o significado da locução "pedagogia socialista" como expressão da teoria marxista da educação. Para tanto o texto foi estruturado em três momentos. No primeiro se explicita o lugar da educação na teoria marxista evidenciando a atualidade dessa corrente filosófica. No segundo momento o texto trata da pedagogia socialista no contexto do marxismo. Finalmente faz-se referência, à guisa de conclusão, à pedagogia histórico-crítica como expressão de uma pedagogia de inspiração marxista.

Palavras-chave: marxismo e educação; marxismo e pedagogia; teoria marxista da educação; pedagogia socialista; pedagogia histórico-crítica.

ABSTRCAT:

\section{MARXISM AND PEDAGOGY}

Starting with the different meanings of the word "socialism" the article covers the relationships among Marxism, education and pedagogy to try to clarify the meaning of the phrase "socialist pedagogy" as expression of the Marxist theory of education. For such the text was structured in three parts. In the first one the place of education in the Marxist theory is exposed, showing how current that philosophical current is. In the second part the text deals with the socialist pedagogy in the Marxist context. Finally, as a conclusion, reference is made to the historical-critical pedagogy as the expression of Marxist-inspired pedagogy.

Key words: Marxism and education; Marxism and pedagogy; Marxist theory of education; sociality pedagogy; historical-critical pedagogy.

\section{MARXISMO E PEDAGOGIA}

O tema desta Mesa Redonda versa sobre a relação entre a teoria marxista e a pedagogia socialista.

Como sabemos, sobre o fundo comum da mobilização das classes trabalhadoras que se formaram no decorrer da Revolução Industrial visando ao controle do processo produtivo, surgiram várias acepções de socialismo. O "Manifesto do Partido Comunista" (MARX e ENGELS, 1968) distingue "socialismo reacionário" onde situa os socialismos feudal, pequeno-burguês e alemão, "socialismo conservador ou burguês" e "socialismo e comunismo crítico-utópicos". Depois Engels (1977) diferenciou socialismo utópico de socialismo científico. Para ele o socialismo utópico "criticava o modo de produção capitalista existente e suas conseqüências, mas não conseguia explicá-lo nem podia, portanto, destruí-lo ideologicamente; nada mais lhe restava senão repudiá-lo, pura e simplesmente, como mau" (p.43).

$\mathrm{Na}$ forma do "socialismo utópico" as idéias socialistas vicejaram no movimento operário europeu ao longo do século XIX, propondo a transformação da ordem capitalista 
burguesa pela via da educação. De acordo com essa concepção a sociedade poderia ser organizada de forma justa, sem crimes nem pobreza, com todos participando da produção e fruição dos bens segundo suas capacidades e necessidades. Para tanto, era mister erradicar a ignorância, o grande obstáculo para a construção dessa nova sociedade. A educação desempenharia, pois, um papel decisivo nesse processo. E a pedagogia socialista então preconizada pelo movimento operário europeu ganhou sua formulação teórica pela contribuição de autores como Saint Simon, Fouriet, Owen e Proudhon.

Mas, como assinalou Engels, era necessário superar o caráter utópico que marcava essa visão do socialismo. Para tanto, impunha-se captar o modo de produção capitalista em suas conexões e em sua necessidade histórica pondo em evidência sua estrutura interna, "seu caráter íntimo" que ainda se encontrava oculto. Essa tarefa foi realizada por Marx que, com a "teoria da mais-valia", desvendou o segredo da produção capitalista. Por esse caminho foi possível ao socialismo tornar-se científico. Nessa acepção o socialismo, em lugar de ser considerado como um ideal a ser conquistado pelo entusiasmo da vontade pondo em prática planos atraentes, era encarado como produto das leis de desenvolvimento do capitalismo, emergindo como sua negação no processo revolucionário de transição para o comunismo conduzido pelo proletariado.

Emerge, nesse novo contexto teórico, uma outra acepção para a expressão "pedagogia socialista". Esta passa a ser entendida como a visão de educação decorrente da concepção marxista da história. É, com certeza, nesse âmbito que se situa o tema desta mesa ao reunir num mesmo enunciado a teoria marxista e a pedagogia socialista.

Tentemos, pois, abordar cada um dos dois aspectos contidos no enunciado. Comecemos pela teoria marxista.

\section{Teoria marxista e educação}

Sabe-se - e isso é reiterado por todos quantos tomam a iniciativa de abordar a educação a partir dos escritos de Marx - que o fundador da filosofia da práxis não se ocupou direta e especificamente da elaboração teórica no campo da educação. No entanto, não faltaram esforços seja para identificar no conjunto da obra as passagens referidas à educação, seja para extrair das análises marxianas sobre a história, a economia e a sociedade derivações de sentido para a educação. Isso pode ser constatado em Dommanget (1972), Os grandes socialistas e a educação: de Platão a Lênin; Rossi (1981), Pedagogia do trabalho: raízes da educação socialista; Dangeville (1976), Marx e Engels: crítica da educação e do ensino; Manacorda (1991), Marx e a pedagogia moderna; e Suchodolski (1966), Teoria marxista da educação, entre outros.

Quanto às passagens dos escritos de Marx referidas à educação, elas se encontram clara e didaticamente destacadas na obra de Manacorda, primeiro rastreando todos os textos na sua integralidade, o que resultou no livro Il marxismo e l'educazione, publicado em 1964. Depois, destacando os aspectos mais significativos, como podemos ver no livro Marx e a pedagogia moderna. Por meio de um cuidadoso estudo filológico visando, como ele mesmo diz, "devolver a Marx o que é de Marx, a Lênin o que é de Lênin e aos outros o que é deles" (MANACORDA, 1991, p. 102), distingue três momentos: a) 1847-1848, quando sobressai o texto do "Manifesto do Partido Comunista", de 1848, correlacionado aos "Princípios do Comunismo", redigido por Engels em 1847; b) 1866-1867, momento em que foi redigido o texto das "Instruções aos delegados do Conselho Geral Provisório do I Congresso da Associação Internacional dos Trabalhadores", entrelaçado e sobreposto às passagens de "O Capital" referidas à educação. Recorde-se que nessa época Marx estava concentrado na redação do Capital, motivo que o levou à decisão de não comparecer ao Congresso que se reuniu no início de setembro de 1866; c) 1875, ano da redação das 
"Notas à margem do Programa do Partido Operário Alemão", conhecidas como "Crítica ao Programa de Gotha.

No primeiro momento (1847-48), destaca-se a seguinte passagem do "Manifesto": "Ensino público e gratuito a todas as crianças. Abolição do trabalho das crianças nas fábricas em sua forma atual. Unificação do ensino com a produção material” (p. 21).

No segundo momento (1866-67), Marx se manifesta, no texto das "Instruções", sobre o conteúdo pedagógico que, a seu ver, deve constituir o ensino de caráter socialista:

Por ensino entendemos três coisas:

Primeira: ensino intelectual;

Segunda: educação física, dada nas escolas e através de exercícios militares;

Terceira: adestramento tecnológico, que transmita os fundamentos científicos gerais de todos os processos de produção e que, ao mesmo tempo, introduza a criança e o adolescente no uso prático e na capacidade de manejar os instrumentos elementares de todos os ofícios.

Com a divisão das crianças e dos adolescentes dos 9 aos 17 anos em três classes deveria estar vinculado um programa gradual e progressivo de ensino intelectual, físico e tecnológico...

A união do trabalho produtivo remunerado, ensino intelectual, exercício físico e adestramento politécnico elevará a classe operária acima das classes superiores e médias (p. 26-27).

Esse texto das "Instruções" se entrelaça com o comentário feito n' O Capital quando Marx efetuou a análise da legislação fabril inglesa:

Seu êxito demonstrou pela primeira vez a possibilidade de vincular o ensino e a ginástica com o trabalho manual e daí também o trabalho manual com o ensino e a ginástica... Do sistema de fábrica, como se pode verificar detalhadamente nos escritos de Robert Owen, nasceu o germe do ensino do futuro que unirá para todas as crianças além de uma certa idade o trabalho produtivo com o ensino e a ginástica, não apenas como método para aumentar a produção social, mas também como único método para produzir homens plenamente desenvolvidos (p. 29).

Essa potencialidade do "ensino do futuro" se manifesta sobre a base da grande indústria, como explicita esta outra passagem d' O Capital:

Um elemento desse processo de subversão, desenvolvido espontaneamente sobre a base da grande indústria, são as escolas politécnicas e de agronomia, um outro elemento são as 'écoles d'enseignement professionel', nas quais os filhos dos operários recebem algum ensino de tecnologia e do manejo prático dos diferentes instrumentos de produção. Se a legislação sobre as fábricas, que é a primeira concessão arrancada, com muito esforço, do capital, combina com o trabalho de fábrica apenas o ensino 
elementar, não há dúvida de que a inevitável conquista do poder político por parte da classe operária conquistará também lugar nas escolas dos operários para o ensino tecnológico teórico e prático (p. 30).

O terceiro momento se materializa, em 1875, com a intervenção de Marx no programa de unificação dos dois partidos operários Alemães quando observa, sobre a educação:

Educação popular (ou ensino elementar) para todos? O que se quer dizer com essas palavras? Acredita-se, talvez, que na sociedade atual (e apenas dessa se trata) o ensino possa ser igual para todas as classes? Ou, então, pretende-se que as classes superiores devam ficar coativamente limitadas àquele pouco de ensino - a escola popular - única compatível com as condições econômicas, tanto dos trabalhadores assalariados quanto dos camponeses?...

Ensino geral obrigatório, instrução gratuita... O parágrafo sobre as escolas deveria, pelo menos, pretender escolas técnicas (teóricas e práticas) em união com a escola popular...

Proibição (geral) do trabalho das crianças... Sua efetivação - se fosse possível - seria reacionária porque, ao regulamentar severamente a duração do trabalho segundo as várias idades e ao tomar outras medidas preventivas para a proteção das crianças, o vínculo precoce entre o trabalho produtivo e o ensino é um dos mais potentes meios de transformação da sociedade atual.

Estão aí, de forma sucinta, as principais menções de Marx ligadas à educação e ao ensino.

Quanto às derivações de sentido para a educação, obtidas a partir da consideração do conjunto da obra de Marx e Engels, quem talvez melhor exemplifique esse esforço é Suchodolski que chegou a publicar, em 1961, o livro "Teoria marxista da educação".

O ponto de partida dessa obra é uma análise da evolução dos problemas pedagógicos nos escritos de Marx e Engels (Cap. I) em que considera a trajetória de seus escritos, desde os primeiros textos até "O Capital". O segundo capítulo é dedicado a mostrar o diagnóstico da atualidade de Marx e Engels em que se analisa o desenvolvimento histórico do capitalismo com as implicações para os indivíduos e as classes, em particular para o proletariado, o problema do tempo livre, a derrocada da ordem classista e a libertação do homem. O terceiro capítulo trata dos problemas da alienação e do fetichismo para concluir com o significado pedagógico da alienação. No terceiro capítulo, denominado "O significado da revolução socialista para a educação", é abordado o caráter de classe do sistema de ensino na sociedade burguesa, o ensino dos filhos de operários, o vínculo ensino-trabalho como gérmen da educação socialista, a organização das massas e a luta pela concepção materialista revolucionária da educação. O capítulo se encerra com considerações sobre a questão da educação moral, cujo centro é a participação dos homens na luta pelo progresso social. Com isso, a visão socialista da educação moral se opõe "tanto aos sistemas burgueses do hedonismo e utilitarismo como também aos sistemas do rigorismo ético e do formalismo" (p. 160). Os capítulos seguintes tratam dos fundamentos da teoria marxista da cultura (Cap. V), da crítica da concepção metafísico-idealista do 
homem (Cap. VI), dos acertos e erros do materialismo metafísico na análise do homem (Cap. VII) e da luta pela teoria materialista da personalidade (Cap. VIII). Finalmente, o capítulo IX, tem caráter de síntese conclusiva versando sobre "o significado de Marx e Engels para a história da pedagogia".

Pela sua atualidade, creio ser pertinente destacar a abordagem feita no capítulo VIII, que trata da teoria materialista da personalidade. Suchodolski mostra a crítica elaborada por Marx e Engels à pedagogia dos utópicos. Mas a maior parte desse capítulo é dedicada à crítica a Stirner, abordando a origem classista da pedagogia individualista, seus fundamentos idealistas e o conceito de individualidade de Stirner. Constata que Marx surpreendeu ao destinar tanto tempo e tanto trabalho a analisar exaustivamente o livro de Stirner, $O$ único e sua propriedade, dedicando-lhe um manuscrito de 424 páginas, quase de igual extensão ao texto criticado. Mas Suchodolski justifica esse empenho ao considerar que "tal concepção sobre o egoísmo real predominava especialmente até fins do século XIX nos círculos dos entusiastas de Nietzsche, para os quais Stirner foi um trágico e esquecido precursor do autor de Also Sprach Zarathustra (Assim falava Zarathustra)" (p. 269).

Conforme Balibar, Stirner não se limita a demolir os gêneros metafísicos tradicionais, de ressonância teológica, como o Ser, a Substância, a Idéia, a Razão, o Bem. Sua crítica "engloba todas as noções universais, sem exceção, antecipando assim certos desenvolvimentos de Nietzsche e o que se chama hoje pós-modernismo" (BALIBAR, 1995, p.46). Stirner não admite nenhuma "grande narrativa". É interessante observar que essa voga pós-moderna, que se reporta a autores como Foucault, e daí, a Nietzsche, teria sido antecipada por Max Stirner a cuja crítica Marx se dedicou, estendendo-se por quase dois terços da Ideologia alemã. O livro de Stirner, O único e sua propriedade, objeto da contestação de Marx, foi publicado em 1844. Para lá de irônico, me parece algo que exige detida meditação o fato de que uma concepção que hoje relega o marxismo a uma visão ultrapassada, própria do século XIX, tenha sido minuciosamente criticada por Marx em 1845.

Contrariamente, portanto, ao que é divulgado hoje pela onda pós-moderna, Marx, situando-se no ponto culminante da trajetória da modernidade, representado por Hegel, buscou empreender a sua crítica de forma contundente, ao mesmo tempo em que procurou desenvolver os elementos da concepção hegeliana que rompiam com o pensamento moderno, cuja expressão máxima nos é dada pela síntese kantiana.

Em contraponto a essa senda científico-filosófica aberta por Marx, nós poderíamos dizer que a maior parte da produção filosófica dos últimos 150 anos não passa de notas à margem do pensamento kantiano que buscam retomar e discutir as conclusões de suas três críticas: a crítica da razão pura, a crítica da razão prática e a crítica do juízo. Com efeito, o positivismo toma como ponto de partida e se constitui num desdobramento da conclusão kantiana segundo a qual apenas a matemática e a física são possíveis como ciência. O vitalismo bergsoniano, assim como o historicismo de Dilthey procura negar a conclusão de Kant segundo a qual não existe intuição intelectual. $\mathrm{O}$ existencialismo e a fenomenologia e, de certo modo, também o positivismo lógico e a filosofia da linguagem partem da constatação kantiana relativa à contraposição entre fenômeno e coisa-em-si, para concluir pela negação dessa dualidade ao afirmar a precedência da existência sobre a essência (existencialismo), a descrição do fenômeno como via de acesso à essência (fenomenologia) e ao considerar que nada existe por trás dos fenômenos (positivismo lógico e filosofia da linguagem). Aliás, sinal dessa força da matriz kantiana é a denominação de escolas neokantianas atribuída aos grupos organizados no interior desses dois últimos movimentos filosóficos. 
E, curiosamente, uma das temáticas que toma corpo nessas correntes e se insinua também no interior do pensamento atual que, de forma genérica e um tanto imprecisa, tem sido chamado de pós-moderno, é a do solipsismo. Presente em Kant, mais explorado por Schopenhauer e abordado por Sartre, tal tema ocupa um lugar importante no positivismo lógico, especialmente em Carnap e Wittgenstein. Este dedica ao tema algumas proposições do "Tractatus", em especial aquelas da série 5.6. Esta, a proposição de número 5.6, tem o seguinte enunciado: "Os limites de minha linguagem denotam os limites de meu mundo" WITTGENSTEIN, 1968, p. 111). Por sua vez, a de número 5.62 fará menção explícita ao solipsismo:

Esta observação dá a chave para decidir da questão: até onde o solipsismo é uma verdade.

$\mathrm{O}$ que o solipsismo nomeadamente acha é inteiramente correto, mas isto se mostra em vez de deixar-se dizer.

Que o mundo é o meu mundo, isto se mostra porque os limites da linguagem (da linguagem que somente eu compreendo) denotam os limites de meu mundo (IBIDEM).

Sartre, por sua vez, fará a seguinte consideração:

Uma psicologia que pretendesse ser exata e objetiva, como o 'behaviorismo' de Watson, teria, em suma, que adotar o solipsismo como hipótese de trabalho. Não se tratará de negar a presença, no campo de minha experiência, de objetos que nós poderíamos nomear 'entes psíquicos', mas somente de praticar uma espécie de époquê no que se refere à existência de sistemas de representações organizadas por um sujeito e situadas fora de minha experiência (SARTRE, 1943, p.284).

Finalmente, observo que o construtivismo, palavra tão difundida hoje no campo pedagógico, é de matriz kantiana, conforme explicitamente o reconheceu Piaget, sua fonte originária.

Ora, se a concepção elaborada por Marx partiu do ponto mais avançado atingido pela modernidade expresso pela filosofia de Hegel, efetuou sua crítica e inverteu os termos do problema posto pelo pensamento moderno desautorizando o idealismo, então não se trata de uma concepção inserida nos limites do pensamento moderno. Não é, pois, uma concepção ultrapassada, mas se insere plenamente no debate contemporâneo. E, pela crítica radical ao idealismo próprio do pensamento moderno, instaura um novo realismo, que, obviamente, não pode ser interpretado como uma volta à metafísica da objetividade anterior à modernidade. Ingressamos, agora, num novo entendimento da objetividade que se beneficiou da incorporação de todos os elementos críticos desenvolvidos no seio da filosofia moderna.

O empenho em compreender e explicar a problemática educativa a partir dessa concepção superadora do pensamento burguês moderno, eis o que se configura como uma teoria marxista da educação. Tal teoria claramente realista, em termos ontológicos, e objetivista, em termos gnosiológicos, move-se no âmbito de dois princípios fundamentais: 1. As coisas existem independentemente do pensamento, com o corolário: é a realidade que determina as idéias e não o contrário; 2 . A realidade é cognoscível, com o corolário: o ato de conhecer é criativo não enquanto produção do próprio objeto de conhecimento, mas 
enquanto produção das categorias que permitam a reprodução, em pensamento, do objeto que se busca conhecer.

\section{Pedagogia socialista}

Dentre as várias acepções denotadas pela palavra "pedagogia", a mais abrangente é, sem dúvida, aquela que a define como teoria da educação. Por aí seria possível rapidamente estabelecer uma conexão entre teoria marxista da educação e pedagogia socialista. Mas devemos nos precaver, pois, ao estabelecermos apressadamente a referida conexão, poderemos estar procedendo a uma relação indevida. E isto, tanto do lado da pedagogia como do lado do socialismo. Com efeito, já observamos que não é todo e qualquer socialismo que pode ser aproximado do marxismo. Por outro lado, se toda pedagogia pode ser considerada teoria da educação, não podemos nos esquecer que nem toda teoria da educação é pedagogia. Na verdade o conceito de pedagogia se reporta a uma teoria que se estrutura a partir e em função da prática educativa. A pedagogia, como teoria da educação, busca equacionar, de alguma maneira, o problema da relação educadoreducando, de modo geral, ou, no caso específico da escola, a relação professor-aluno, orientando o processo de ensino e aprendizagem. Assim, não se constituem como pedagogia aquelas teorias que analisam a educação pelo aspecto de sua relação com a sociedade não tendo como objetivo formular diretrizes que orientem a atividade educativa, como é o caso das teorias que chamei de "crítico-reprodutivistas".

Considerando a especificidade da teoria pedagógica, podemos observar que nem toda teoria marxista da educação pode ser considerada pedagogia. Assim, não se pode negar o caráter marxista da teoria da escola como "aparelho ideológico de Estado", elaborada por Althusser (s/d.). E, como se trata de uma teoria que busca explicar o sentido e o caráter da educação na sociedade capitalista, não se lhe pode negar, também, o caráter de teoria da educação. Não é, porém, pedagogia. Igualmente, a "teoria da escola dualista", elaborada por Baudelot e Establet (1971), se fundamenta no marxismo podendo, pois, ser considerada uma "teoria marxista da educação". Mas não se trata de uma teoria pedagógica.

Parece, pois, ser possível, sem maiores dificuldades, concluir que a pedagogia socialista compatível com o marxismo será aquela que, fundando-se na perspectiva do "socialismo científico", busque equacionar o problema da relação professor-aluno, orientando o modo como se deve realizar o processo de ensino e aprendizagem, com tudo o que essa ação implica e que deverá ser sistematizado na teoria pedagógica correspondente.

No entanto, um outro aspecto que não deve ser perdido de vista é que a expressão "pedagogia socialista", do ponto de vista marxista, só faz sentido como uma orientação pedagógica em períodos de transição entre a forma social capitalista com a correspondente pedagogia burguesa e a forma social comunista na qual - e apenas nela - será possível emergir uma pedagogia propriamente marxista, vale dizer, uma pedagogia comunista.

Esse caráter de transição da pedagogia socialista pode ser ilustrado de modo claro por meio do livro de Suchodolski (1976), Fundamentos de pedagogia socialista. O autor constata, no prefácio, que educar com os olhos voltados para o futuro não elide o fato de que educamos "aqui e agora", em "condições de dura luta pelo progresso técnico e econômico, pelo incremento da produtividade do trabalho, pelo aumento das colheitas por unidade de cultivo, pela redução dos custos de construção das habitações e pela aceleração de seu ritmo, pela liquidação das atitudes associais dos indivíduos, o egoísmo e a libertinagem, o alcoolismo e a preguiça, pela superação dos vestígios - ainda solidamente implantados - de uma ideologia estranha e de modos de vida estranhos". E Suchodolski prossegue indagando sobre "qual das duas esferas, o ideal do futuro ou a realidade atual, 
determina o conteúdo e o caráter da educação socialista" (p. 7) respondendo que "o que precisamente caracteriza a educação de tipo socialista é, concretamente, a unidade de ambos os fatores cronológicos: o presente e o futuro" (p. 8). Assim, tendo como referência a situação da Polônia no início da segunda metade do século XX inicia a análise com o "caráter antagônico da civilização burguesa e do socialismo" (Cap. I) abordando, na seqüência, "a civilização socialista: ontem, hoje, amanhã" (Cap. II), as "finalidades da educação" (Cap. III), "heterogeneidade e unidade da educação" (Cap. IV), "a personalidade e sua integração" (Cap. V), "a difícil problemática da educação no mundo moderno" (Cap. VI), para concluir com os "princípios filosóficos da pedagogia socialista" (Cap. VII), assim sintetizados:

1. Absoluta originalidade da pedagogia socialista: "a atividade pedagógica na época do socialismo deve assumir um caráter tão novo como a própria realidade social dessa época, sem precedentes na história" (p. 219);

2. Caráter ativo do ser humano: esse princípio deriva do materialismo dialético e histórico em sua polêmica com a teoria sensualista. Contra o sensualismo que se manifestava como uma filosofia que situava o homem como um mero espectador da realidade, refletindo "a experiência de uma classe que era a classe possuidora e não a classe trabalhadora" (p. 225), o marxismo afirmava resolutamente "a atividade sócio-histórica e material dos homens" (p. 226). Portanto, contra a pedagogia sensualista, que "considerava o meio ambiente como a suprema instância educativa" (p. 225), a pedagogia socialista afirma que o próprio ambiente necessita ser educado. Assim, do mesmo modo que a história é obra dos homens, a educação, "a fortiori", é obra dos próprios homens;

3. Caráter material e social da atividade humana: esse princípio deriva da polêmica de Marx com Hegel, afirmando que, na formação do homem, é a prática material o elemento determinante e não as idéias. "Por isso mesmo, o trabalho - e não a contemplação ou as sensações - é, a juízo de Marx, o traço essencial do homem, o fator que o cria e que o torna a modelar continuamente" (p. 228). Contra a pedagogia idealista que raciocinava de modo substantivo, "buscando o que há de idêntico na diversidade", a pedagogia socialista raciocina objetivamente, "centrando sua atenção não na "unidade dos objetos, concebida como a unidade da substância dissimulada nas diferenças', mas na própria diferença e suas causas reais" (p. 232);

4. Formação da consciência e transformação da vida: esse princípio decorre da crítica de Marx a Feuerbach. Por ele a pedagogia socialista se contrapõe a toda filosofia e pedagogia da consciência, seja ela de origem sensualista, idealista e também materialista do tipo feuerbachiano, afirmando a atividade dos homens como o elemento determinante do mundo humano compreendido, ao mesmo tempo, como domínio da natureza e criação das novas formas da vida social;

5. A prática revolucionária: esse princípio se explicita claramente na terceira tese sobre Feuerbach. Esta, após considerar que "a teoria materialista segundo a qual os homens são produto das circunstâncias e da educação esquece que são precisamente os homens que modificam as circunstâncias e que o educador necessita, por sua vez, ser educado", conclui: "a coincidência entre a mudança das circunstâncias e da atividade humana só pode ser concebida e entendida racionalmente como 
prática revolucionária" (MARX, 1974, P.666). Com esse entendimento, a pedagogia socialista se distingue de todas as teorias positivistas e pragmáticas, entre elas, a pedagogia de Dewey. Esta acreditava na possibilidade de se instaurar uma comunidade na qual os indivíduos se comunicariam entre si com base em sua atividade criadora e no constante intercâmbio de experiências realizadas na transformação prática da realidade (p. 239). Mas estava longe de conceber essa ação transformadora como prática revolucionária.

Suchodolski encerra sua abordagem dos princípios filosóficos da pedagogia socialista tecendo algumas considerações sobre "a duração histórica dos princípios da pedagogia socialista" (p. 240-242), observando que os princípios filosóficos mencionados guiaram a luta pelo socialismo nas condições da sociedade burguesa e mantêm todo o seu significado nas condições do triunfo da revolução socialista. Claro que ele estava se referindo aí à instauração do socialismo na União Soviética e no Leste Europeu, especificamente em seu país, a Polônia.

\section{Conclusão: para uma pedagogia de inspiração marxista}

À vista das considerações anteriores concluo que, para a construção de uma pedagogia inspirada no materialismo histórico, não basta recolher as passagens das obras de Marx e Engels diretamente referidas à educação, como o fizeram Dommanget (1972, p. 321-348), Rossi (1981; 1982), Dangeville (1976) e mesmo Manacorda (1964; 1991), que acrescenta lúcidas e pertinentes reflexões úteis, sem dúvida, à construção de uma pedagogia marxista. Também não é suficiente perscrutar as implicações educacionais do conjunto da obra dos fundadores do materialismo histórico, como o fez Suchodolski (1966).

Penso que a tarefa da construção de uma pedagogia inspirada no marxismo implica a apreensão da concepção de fundo (de ordem ontológica, epistemológica e metodológica) que caracteriza o materialismo histórico. Imbuído dessa concepção, trata-se de penetrar no interior dos processos pedagógicos, reconstruindo suas características objetivas e formulando as diretrizes pedagógicas que possibilitarão a reorganização do trabalho educativo sob os aspectos das finalidades e objetivos da educação, das instituições formadoras, dos agentes educativos, dos conteúdos curriculares e dos procedimentos pedagógico-didáticos que movimentarão um novo éthos educativo voltado à construção de uma nova sociedade, uma nova cultura, um novo homem, enfim.

Fiz uma primeira aproximação nessa direção ao formular a proposta da pedagogia histórico-crítica. Para tanto, recorri a alguns textos fundantes de Marx, especificamente à distinção entre produção material e não-material, tendo em vista a caracterização na natureza e especificidade da educação (MARX, 1978). Igualmente recorri ao texto "O método da economia política" (MARX, 1973, p. 228-240) ao estruturar o método da pedagogia histórico-crítica, ocasião em que indiquei de onde eu retirava o critério de cientificidade do método pedagógico proposto: "não é do esquema indutivo tal como o formulara Bacon; nem é do modelo experimentalista ao qual se filiava Dewey. É, sim, da concepção dialética de ciência tal como a explicitou Marx no "método da economia política'”, concluindo que "o movimento que vai da síncrese ('a visão caótica do todo') à síntese ('uma rica totalidade de determinações e relações numerosas') pela mediação da análise ('as abstrações e determinações mais simples') constitui uma orientação segura tanto para o processo de descoberta de novos conhecimentos (o método científico) como para o processo de transmissão-assimilação de conhecimentos (o método de ensino)" (SAVIANI, 2007a, p.74). 
Além de Marx, Gramsci que, dentre os teóricos marxistas, foi aquele que mais avançou na discussão da questão escolar, alimentou minhas análises pedagógicas. Inspirado nele lancei mão da categoria "catarse" para caracterizar o quarto passo do método da pedagogia histórico-crítica, constitituvo do momento culminante do processo educativo, quando o educando ascende à expressão elaborada da nova forma de entendimento da prática social. Pareceu-me que a acepção gramsciana do termo "catarse", entendendo-a como a "elaboração superior da estrutura em superestrutura na consciência dos homens" (GRAMSCI, 1978, p. 53) se revelava perfeitamente adequada para exprimir o momento da efetiva incorporação dos instrumentos culturais, transformados, pela mediação do trabalho pedagógico, em elementos ativos de transformação social (SAVIANI, 2007a, p. 72).

Também em Gramsci me inspirei para indicar o caminho para a construção de um currículo escolar adequado às condições atuais próprias desse período de transição da forma social capitalista para uma sociedade socialista. Expressei esse encaminhamento em trabalho recente (SAVIANI, 2007b, p. 128-130) nos seguintes termos: Buscando encaminhar essa questão, o eixo da organização da educação escolar nas condições da nossa época me foi suscitado pela problematização efetuada por Gramsci (1975, vol. III, p. 1544-1546; na edição brasileira, 1968, p. 134-136) em sua reflexão sobre a questão escolar. Reporto-me à passagem em que ele se referia à centralidade que tinha a cultura grecoromana na velha escola, traduzida no cultivo das línguas latina e grega e das respectivas literaturas e histórias políticas. Constituía-se, por esse caminho, o princípio educativo da escola tradicional, "na medida em que o ideal humanista, que se personifica em Atenas e Roma, era difundido em toda a sociedade", sendo "um elemento essencial da vida e da cultura nacionais". O latim, como língua morta, permitia o estudo de um processo histórico inteiro, analisado desde o seu nascimento até sua morte. Mas Gramsci acrescenta: "morte aparente, pois sabe-se que o italiano, com o qual o latim é continuamente comparado, é latim moderno". Estudando a história dos livros escritos em latim, sua história política, as lutas dos homens que falavam latim, o jovem submergia na história, adquirindo "uma intuição historicista do mundo e da vida, que se torna uma segunda natureza, quase uma espontaneidade, já que não é pedantemente inculcada pela 'vontade' exteriormente educativa". E acrescenta: "Este estudo educava, (sem que tivesse a vontade expressamente declarada de fazê-lo) com a mínima intervenção 'educativa' do professor: educava porque instruía". Claro, ele assinala, isto não se devia a uma suposta virtude educativa intrínseca ao grego e ao latim. Esse resultado era produto de toda a tradição cultural, viva não apenas na escola, mas principalmente fora dela. Uma vez "modificada a tradicional intuição da cultura", a escola entrou em crise e com ela entrou em crise o estudo do latim e do grego. Daí a conclusão: "Será necessário substituir o latim e o grego como fulcro da escola formativa; esta substituição ocorrerá, mas não será fácil dispor a nova matéria ou a nova série de matérias numa ordem didática que dê resultados equivalentes".

Desde a primeira vez em que li essas passagens nos idos da década de 1970, sempre me perguntava sobre a ou as matérias que pudessem desempenhar numa nova escola adequada aos tempos atuais, papel equivalente àquele desempenhado pelo latim e pelo grego na velha escola. E uma idéia começou a tomar forma em meu espírito. Essa idéia é a de que a História seria exatamente essa matéria que ocuparia o lugar central no novo princípio educativo da escola do nosso tempo: uma escola unitária porque guiada pelo mesmo princípio, o da radical historicidade do homem e organizada em torno do mesmo conteúdo, a própria história dos homens, identificado como o caminho comum para formar indivíduos plenamente desenvolvidos. Com efeito, que outra forma poderíamos encontrar de "produzir, em cada indivíduo singular, a humanidade que é produzida histórica e 
coletivamente pelo conjunto dos homens" (SAVIANI, 2005, p. 13), senão fazendo-os mergulhar na própria história e, aplicando o critério do "clássico", permitir-lhes vivenciar os momentos mais significativos dessa verdadeira aventura temporal humana?

Eis aí indicadas algumas aproximações do que poderia ser uma pedagogia marxista, isto é, uma pedagogia inspirada e construída em consonância com os princípios teóricopráticos do materialismo histórico. Claro que esse processo de construção necessita ter prosseguimento, não se constituindo em uma tarefa individual, mas coletiva. No que se refere à pedagogia histórico-crítica esse trabalho continua se desenvolvendo com o concurso de diversos colaboradores que vêm tentando explorar as potencialidades dessa concepção pedagógica em campos como o da didática (GASPARIN, 2002; Geraldo, 2006); psicopedagogia (SCALCON, 2002); ensino de ciências (SANTOS, 2005); e educação infantil (MARSIGLIA, 2005).

\section{Bibliografia}

ALTHUSSER, Louis (s/d.), Ideologias e aparelhos ideológicos de Estado. Lisboa, Presença.

BALIBAR, Étienne (1995), A filosofia de Marx. Rio de Janeiro, Jorge Zahar.

BAUDELOT, Christian \& ESTABLET, Roger (1971). L'école capitalista en France. Paris, Maspero.

DANGEVILlE, Roger (Org.), MARX E ENGELS, Critique de l'éducation et de l'enseignement. Paris, Maspéro, 1976.

DOMMANGET, Maurice (1972), Los grandes socialistas y la educación: de Platón a Lenin. Madrid, Fragua.

ENGELS, F. (1977), "Do socialismo utópico ao socialismo científico". In: MARX, Karl e ENGELS, Friedrich, Textos 1. São Paulo, Edições Sociais, 1977, p.5-60.

GASPARIN, João Luiz (2002). Uma didática para a pedagogia histórico-crítica. Campinas, Autores Associados.

GERALDO, Antonio Carlos Hidalgo (2006). Didática de ciências e de biologia na perspectiva da pedagogia histórico-crítica. Bauru, UNESP, Tese de Doutorado.

GRAMSCI, Antonio (1968), Os intelectuais e a organização da cultura. Rio de Janeiro: Civilização Brasileira.

GRAMSCI, Antonio (1975), Quaderni del carcere. Torino: Einaudi.

GRAMSCI, Antonio (1978), Concepção dialética da história, 2ª ed. Rio de Janeiro, Civilização Brasileira.

MANACORDA, Mario Alighiero (1964), Il marxismo e l'educazione. Roma, Armando Armando.

MANACORDA, Mario Alighiero (1991), Marx e a pedagogia moderna. São Paulo, Cortez/Autores Associados.

MARSIGLIA, Ana Carolina Galvão (2005). Como transpor a pedagogia histórico-crítica para a prática pedagógica do professor na educação infantil? Bauru, UNESP, Trabalho de Conclusão do Curso de Pedagogia.

MARX, Karl (1973), Contribuição para a crítica da economia política. Lisboa, Estampa. 
MARX, Karl (1974), Tesis sobre Feuerbach. In: MARX, Karl e ENGELS, Friedrich (1974), La ideología alemana. Montevideo / Barcelona, Pueblos Unidos / Grijalbo, p. 665668.

MARX, Kart (1978), Capítulo VI (inédito), O Capital, Livro I. São Paulo, Ciências Humanas.

MARX, Karl \& ENGELS, Friedrich (1968), Manifesto do partido comunista. São Paulo, Escriba.

ROSSI, Wagner Gonçalves (1981), Pedagogia do trabalho: raízes da educação socialista. São Paulo, Moraes.

SANTOS, César Sátiro (2005). Ensino de ciências: abordagem histórico-crítica. Campinas, Autores Associados.

SARTRE, Jean-Paul (1943), L'être et le néant. Essai d'ontologie phénoménologique. Paris, Gallimard.

SAVIANI, Dermeval (2005), Pedagogia histórico-crítica: primeiras aproximações, $9^{\mathrm{a}}$ ed. revista e ampliada. Campinas: Autores Associados.

SAVIANI, Dermeval (2007a). Escola e democracia, 39a ed. Campinas, Autores Asociados.

SAVIANI, Dermeval (2007b). "Pedagogia: o espaço da educação na universidade". Cadernos de Pesquisa, v. 37, n. 130, jan./abr. 2007, p. 99-134.

SCALCON. Suze Gomes (2002). À procura da unidade psicopedagógica: articulando a psicologia histórico-cultural com a pedagogia histórico-crítica. Campinas, Autores Associados.

SUCHODOLSKI, Bogdan (1966). Teoría marxista de la educación. México, Grijalbo.

SUCHODOLSKI, Bogdan (1976). Fundamentos de pedagogía socialista. Barcelona, Laia. WITTGENSTEIN, Ludwig (1968), Tractatus logico-philosophicus. São Paulo, Nacional/USP.

\footnotetext{
${ }^{1}$ Intervenção na Mesa IV - Teoria Marxista e Pedagogia Socialista, integrante da programação do III EBEM (Encontro Brasileiro de Educação e Marxismo). Salvador, 14 de novembro de 2007.

${ }_{2}^{2}$ Professor Emérito da UNICAMP e Coordenador Geral do Grupo Nacional de Estudos e Pesquisas HISTEDBR.
}

Recebido em: $\quad 10 / 11 / 10$

Aprovado em: $18 / 01 / 11$ 